\title{
Archiving the Sonic Ephemeral: Towards a classification of sound installation documentations through spatial audio features
}

\author{
Nicolas D’Aleman Arango \\ Nicolas.Daleman@hpi.de \\ Hasso Plattner Institute for Digital Engineering \\ Potsdam, Germany
}

\begin{abstract}
This paper proposes the application of audio feature extraction for the classification of sonic documentations of the works presented during the Singuhr Hoergalerie Project from 1996 to 2014. More specifically, I utilize the Stereo Panning Spectrum Features to discern some of the relationships between the artworks based on the spatial characteristics of said documentations. The first part of this paper addresses the theoretical concerns that emerge from documenting a form of art that champions ephemerality as one of its core characteristics. Audio recordings force sound installations into an ontological reality and effectively positions them in the musical realm, thus subjecting them to a one-dimensional interpretation. An approach to overcome this paradox is built upon Kersten Glandien's proposal to analyze sound art. The second part describes the technical processes of examining the Singuhr recordings through the proposed algorithm. The results present a novel form of approaching sonic documentations by analyzing spatial relations between audio sources, and how to incorporate them into additional documentary and archival material.
\end{abstract}

\section{CCS CONCEPTS}

- Applied computing $\rightarrow$ Sound and music computing; Digital libraries and archives.

\section{KEYWORDS}

sound art, spatial audio, stereo panning spectrum, documentation

\section{ACM Reference Format:}

Nicolas D'Aleman Arango. 2021. Archiving the Sonic Ephemeral: Towards a classification of sound installation documentations through spatial audio features. In 8th International Conference on Digital Libraries for Musicology (DLfM2021), July 28-30, 2021, Virtual Conference, GA, USA. ACM, New York, NY, USA, 5 pages. https://doi.org/10.1145/3469013.3469015

\section{INTRODUCTION}

As Andreas Engström and Åsa Stjerna point out, the German term Klangkunst has a much narrower designation than the English

Permission to make digital or hard copies of all or part of this work for personal or classroom use is granted without fee provided that copies are not made or distributed for profit or commercial advantage and that copies bear this notice and the full citation on the first page. Copyrights for components of this work owned by others than the author(s) must be honored. Abstracting with credit is permitted. To copy otherwise, or republish, to post on servers or to redistribute to lists, requires prior specific permission and/or a fee. Request permissions from permissions@acm.org.

DLfM2021, fuly 28-30, 2021, Virtual Conference, GA, USA

(c) 2021 Copyright held by the owner/author(s). Publication rights licensed to ACM ACM ISBN 978-1-4503-8429-2/21/07 ..\$15.00

https://doi.org/10.1145/3469013.3469015 term Sound Art and refers almost exclusively to sound installations and sound sculptures that utilize sound as material. [7] The works in this genre usually bring attention to the acoustic, spatial and architectonic characteristics of sound. They create a connection between auditive and visual elements, and between time-based and space-based arts, while avoiding any association with performance practices. For Helga de la Motte-Haber, the need of addressing sitespecificity as a structural part of its practice, positions Klangkunst within the context of land art which "turns places into a subject of discussion in their own right." [5]

Many works of Klangkunst go beyond the articulation of space through sound and establish a multi-dimensional form of perception situated between the sonic and the visual. This inserts a layer of complexity to the documentation of such artworks: not only media needs to be included in the documentation process, but also the visual material and its interaction within the overall experience of the piece. The one-dimensional perspective captured by a pair of microphones obliterates the core elements of Klangkunst works, namely acoustic spatial awareness, multimodal forms of perception and time non-linearity.

Furthermore, the sonic material found in pieces of Klangkunst often challenges traditional musical associations and tend to focus on sonic elements that explore spectral and semantic aspects of non-musical material such as noise, soundscapes, and speech. Klangkunst avoids being scrutinized by the pre-established structures developed for musical analysis. Although some of the data acquired through spectral analysis (such as finding musical pitches of textures) could be significant in the analysis of some sound installations, this is often irrelevant in the complete framework of the artwork as a whole. Hence, the ordinary tools provided by Music Information Retrieval are not adequate to obtain relevant data about the sonic characteristics of the documentation sound art. A careful analysis of the spatial components of sound has the potential to reveal overlooked details about site-specific sound installations, given that acoustic spatial perception represents one of the main elements of this form of art.

Considering the challenges of the documentation practices in sound art installations opens up the discussion of archiving ephemeral sonic events and other site-specific nuances that are becoming more present in contemporary music. This modest proposal for analyzing spatial features of documentations could potentially be applied to more traditional musical settings (e.g. Luigi Nono's late oeuvre or electroacoustic music spatial set-ups). Likewise, it serves as a form to question and challenge the ways in which documentation practices are preconceived, and how could Music Information Retrieval broaden its applications into the artistic practice. 


\section{SOUND ART ANALYSIS}

Kersten Glandien's proposal to analyze sound art recognizes the need to take into account the "non-sounding" components of artwork. [8] This includes the visual and spatial elements as well as the multisensory experience conveyed by perception of space through sound. Audio recordings are therefore less than ideal tools for the analysis of sound art, given that they cannot grasp the totality of spatial three-dimensionality of sound perception. The linear and monosensory modes of perception forced by the sound recording challenge the nature of the installation as an open work.

Bringing into discussion Umberto Eco's ideas, Glandien notes that sound installations avoid any linear narrative and rather present multiple possibilities of meaning that depend on the individual perception and reception of the work. [8] Eco notes that every work of art is open to a virtually unlimited range of possible readings, but that the open work is "to be seen as the actualization of a series of consequences whose premises are firmly rooted in original data provided by the author." [6] What situates sound installations as open works is specifically the auditory design of the pieces (i.e., the data provided by the author) and not necessarily the overall visual and spatial component that complements it. Moreover, it is the sonic element of the installation what makes it sound art, and not just installation art with a sonic component.

In musical practices an open work is an invitation (to the performer) to create the work together with the author. In sound installations the perceiver becomes the performer who creates the work together with the artist. Even though the totality of a sound installation cannot be grasped by an audio recording, or by a single witness, every subjective perception of a piece has the potential to create an equally valid interpretation. Since the work is perceived differently by each subject, it is created while it is being listened and perceived: a phenomenological approach put in practice. In that sense, a computational analysis of the sonic components of an installation is as valid as any other form of analysis, since it is the act of the listening machine that actualizes the piece itself.

It is important to emphasize that these recordings are conceived as documents that do not represent the totality of the artwork, nor a particular aesthetic approach to the documentation itself. Nevertheless, the preconceived value of sound recordings as representations of music is carried over to the context of sound art. Contrary to the practices of electroacoustic music, these audio examples are not the end result of the art work, nor do they function as "scores" for re-installation or re- interpretation, even though they run the risk of being mistaken for the artwork itself. In other words: "In order to advance the academic discourse on Sound Art, and raise awareness about it, concessions will have to be made - so long as we remain aware of the situation, and do not take the recording for the actual work" [8]. In that sense, the documentarian - be it the artist himself or the audio engineer- creates a sonic impression of the work, an own interpretation of an open work, that is as valid as the multiple interpretations and constructions that can arise from documentary practices.

Once a perspective of the sound installation is captured into a sound recording, it becomes an ideal material for computational analysis. Nevertheless, just as the score is a graphical representation of music, the recording is just an imprint of sound, and as such it can acquire the same aesthetic qualities as an art object itself. Thus, the analysis of sound art questions the essence of the artwork itself: What is a work of sound art? how can we identify it? This ontological discomfort is further accentuated by a proposal of sound analysis via computational means. As Alan Marsden claims: "The computational analyst is therefore effectively placed in a position at one extreme pole of the ontological debate, where pieces of music, or at least their manifestations used for analysis, are entities of which every feature is fixed." [9] But "(T)he fact that one cannot be certain that the input to computational analysis covers all the necessary information about the piece does not render the analysis impossible" [9] These audio documents can by themselves already tell us a lot about the installations themselves, and subject to be analyzed archived and catalogued according to their audio features.

\section{STEREO PANNING FEATURES IN PRACTICE}

The Singuhr project (1996-2014) played a significant role in the establishment of Klangkunst as a distinctive genre. It is the application of the theoretical framework that evolved from the mid and late 20th century discourse of experimental music. The first part of the Singuhr project was developed between 1996 and 2006 in the Parochialkirche, a church in Berlin Mitte. The second part of the Singuhr project took place between 2007 and 2014 in the Wasserturm and the Wasserspeicher, old water reservoirs in Berlin. Two catalogues were released, one for each of the periods of time: Singuhr in Parochial 1996-2006[1] and Singuhr Horgalerie 2007-2014[2], that contain a brief explanation of the pieces exhibited, as well as photos, sketches, technological and artistic materials, and a DVD with sound examples.

Some of the fifty-one works presented during the time frame of the residency in the Parochialkirche engage with different spaces in the church, such as the nave, the belfry, stairway, the platform, the steeple hall and the west conch. Some of the recordings were made by the artists while others were made by sound engineers. Conversely, most of the recordings in the Wasserturm and Wasserspeicher were made by Timour Klouche, which makes them somewhat consistent. Each sound example on the DVD comes with an outline of the space in which it was recorded showing the location of the microphone. In many of the sound examples there is a clear compromise when the nuances of the pieces cannot be captured in their totality. Many of the pieces have long duration or are composed generatively. Others have different positions in the room (particularly in the Church) from which they could be experienced.

My approach explores the use of Stereo Panning Spectrum as described by [13]. SPS is a stereo audio feature that calculates the general balance of a stereo signal per frequency bands. Its main purpose is to analyze the production methods of a stereo image on stereo track. In their words "The proposed features can be viewed as a first attempt to capture the extra-musical information related to the production process through Music Information Retrieval” [13]. In short, SPS compares the left and right channel of a stereo signal and looks for the difference in amplitude per segment of time given by the window size, per frequency bin. It reveals the ways in which the panning characteristics of a given recording behave over time and in each frequency range. SPS also is helpful to discover 
mono duplicated signals and is also sensitive to noise information. Stereo pairs inherently leak information of one channel into the other, while precise panning positioning is only possible in studio productions.

The use of SPS is convenient for the analysis of sound art recordings for various reasons. First, it is presented as an analysis of production techniques rather than an acoustic analysis. Thus, we are analyzing how the documentations were recorded, instead of an analysis what is recorded. Second, the analysis of a panning spectrum reveals change over time in the stereo image: Clear distinction between left and right channel indicates several audio sources, multichannel installations or recording studio editions, whereas pieces with a regular (i.e., noisy) distribution through the stereo image indicates installations that interact directly with the architectural characteristics of space and its perceptual properties. Third, because the difference of energy per window bin is frequency related, these features can reveal more information about the sound sources that were used in the installation, unlike a simple phase correlation measurement. For example, movement in the low frequency bands, indicates the use of one or more sub-woofers, and / or the presence of sub-harmonic beatings, as seen in Fig. 1.
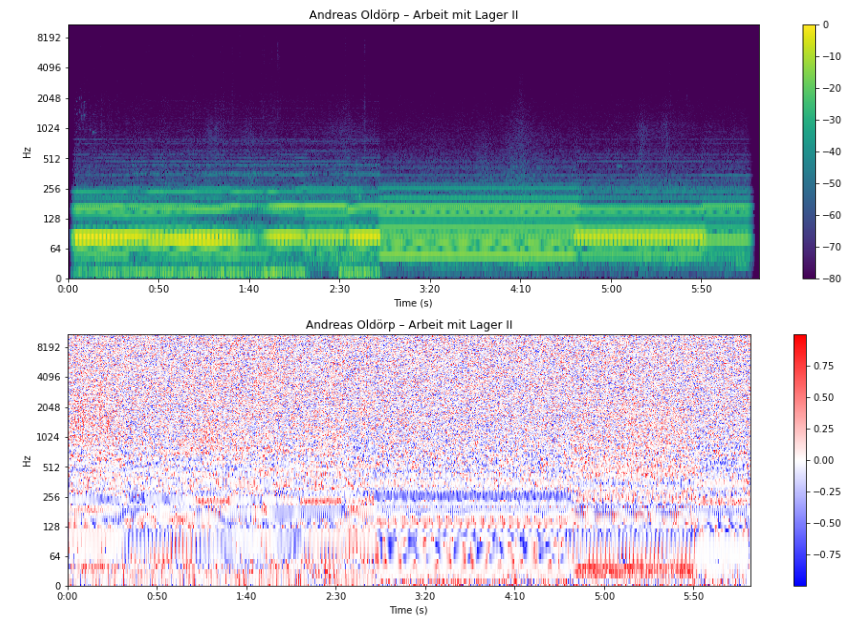

Figure 1: Spectrogram and Stereo Panning Spectrum Visualization of Andreas Oldörp's Arbeit mit Lager II

Stereo Panning Spectrum Features are helpful to recognize some strategies to sound spatialization within the artworks, by making evident the different approach to auditive design within the installations: between pieces that have an immersive or discrete use of space. Through spectral visualization, it is easy to recognize audio tracks that have been recorded live, produced in the studio, or a mix of both. The presence of reverberation or background noise in these tracks is often an indicator of the aesthetic approach of the artist.

A 16-dimensional vector of Stereo Panning Spectrum Features was extracted from each of the 112 audio samples of the Singuhr tracks found in the DVDs. The resulting vector was then averaged, representing the overall amount of movement in the stereo image for each track. By sorting the files according to this number, the results are already quite satisfactory. (see Table 1) The pieces with the highest SPSF average e.g. Jutta Ravenna's Traum und Wahrheit or Christina Kubisch's DreiundDreißig Felder Vier Tafeln are composed by an amount of small single sources of audio, either speakers (Christina Kubisch) subsonic frequencies (Jan-Peter E.R. Sontag) or material devices such as percussion (Martin Riches) or electronic circuits (Jutta Ravenna or Erwin Stache's Klangkästen). The pieces with the lowest SPSF average are either recordings that are monophonic (Carsten Nicolai's Kosmos) or have a stable stereo image such as Johannes Obenthür and Martin Supper's Stillegung or Miki Yui's Innerest. In most of these pieces there are big ambitious structures that engage with the architectonical space as a whole, e.g., Andreas Oldörp's “Singing Flames”, Obenthür and Supper's structures, or Yui's paper sculpture. (Fig. 2)
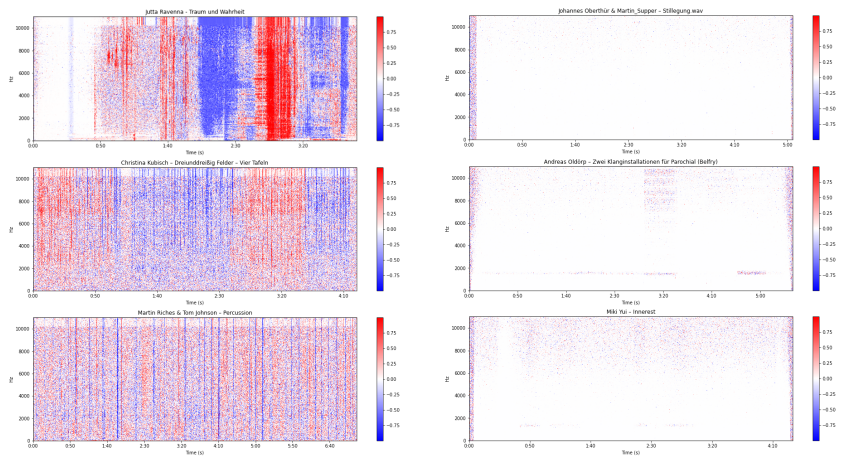

Figure 2: Visual Comparison of SPS between top indexes and bottom indexes in the table.

\section{FURTHER CONSIDERATIONS}

Creating a first approach to analyze and classify the documentation of sound installations is a manifold exercise. First, the goal is to demystify the aura behind the sound installations and challenge the assumptions about sound art. The fact that these sonic documentations exist makes them already available to scrutinize and analyze. Furthermore, getting to know the sonic characteristics of this installation through the lenses of audio analysis, opens the opportunity for new discussions regarding indexing, genre, classification and archival processes. Auditive references help us to better understand sound installations as pieces of art that engage with sonic material, rather than pieces of installation art that happen to have a sonic component. Documentation of sound art offer an interpretation of a piece of art, a particular complete work under the framework of Eco's 'open work.'

Once we are able to clearly recognize these characteristics on the audio documentation of a sound art installation, further questions can be asked about the intentions and experiences of the piece. If the piece is "immersive", how is this achieved sonically? What kind of spatial perceptions are in play in such pieces? If the piece has a more dynamic use of space, what are the sound sources? How many are there? What are their sonic characteristics? How could they affect our perception of space? Ultimately, how do we, as listeners and creators of the piece, engage with the data given by the author? Some of these questions could be asked when considering 
Table 1: Stereo Panning Spectrum Features Averages

\begin{tabular}{ccc}
\hline Position & Track & Index \\
\hline 1 & Jutta Ravenna - Traum und Wahrheit & 0.00492 \\
2 & Christina Kubisch - Vier Tafeln & 0.00439 \\
3 & Martin Riches \& Tom Johnson - Percussion & 0.00438 \\
4 & Edwin van der Heide \& Marnix de Nijs - Spatial Sounds & 0.00432 \\
5 & Jan Peter E.R. Sonntag - Sub Sonus - Spatium Campanarum & 0.00431 \\
$\ldots$ & $\ldots$ & $\ldots$ \\
108 & Miki Yui - Innerest & 0.00097 \\
109 & Carsten Nicolai - Kosmos+Turm - Bausatsz.Noto & 0.00068 \\
110 & Andreas Oldörp - Zwei Klanginstallationen für Parochial (Belfry) & 0.00060 \\
111 & Johannes Oberthür \& Martin Supper - Stillegung & 0.00047 \\
112 & UdK Berlin Sound Studies - Klangspeicher & 0.00026 \\
\hline
\end{tabular}

the practical details of the documentation processes themselves: What kind of recording techniques suit better the documentation of this and that sound installation? Sound art documentation as an artistic practice, gains its own aesthetic ground mainly by weighting what is left behind and what is included.

Furthermore, this research can fuel the discussion regarding reinstallations of sound art and site specificity. How important is the specific space and how can it be recreated or compromised in order to re-create a similar experience as the original? Conversely, how can the sound art documentarian convey a particular sense of space within the sound recording of a piece? Audiovisual documentation of sound installations surfaces as a logical response to archive some of the multi-modal components of the artwork. This practice would support the idea of sound installations as form of media art (c.f. [3]), rather than a practice that stems from the musicological tradition as exposed by Straebel. [10] Some consideration regarding the documentation of sound installations through audiovisual means has been explored by [14], who also encourages a more thoughtful documentation from part of the artist, as constituent part of the whole artwork.

The database of sound installations presented and curated by Singuhr project is clearly a first approach to create a more comprehensive database of sound installations. The ImMAap project was one of the first attempt to systematically classify this form of artworks in the form of a relational multimedia database and an immersive installation. [11] The project included examples from the electroacoustic and experimental music realm, thus adhering to the broader definition of the English-speaking term "Sound Art" that [7] proposes. While this project benefits from the flexibility of a complex ontology with far-reaching metadata entries to make connection between the artworks, there is no clear relationship in the form of sound or aesthetic content. Unfortunately, as a PhD dissertation, further maintenance of the database is no longer taking place.

\section{CONCLUSIONS}

I have presented a somewhat unusual approach to the classification of a somewhat unusual form of sonic documentation. This idea developed from my own curiosity on Listening Machines as tools for creativity, and their application in an artistic set up. Nevertheless,
I deem this discussion important since, as Straebel has claimed, the new generation of sound artists appear to be always reinventing the wheel, leaving us with the sensation that the same ideas have been used to exhaustion. [10] Arguably one of the reasons for this is the lack of tools for engagement with the sonic archive. My proposal is to find new materials by reconsidering the ideas of the past, and not to only relying on subjective descriptions of pieces or technical and acoustic analysis, but also by including machines as agents of creativity.

Novel applications of acoustic analysis could be relevant to further analyze and classify sound installations. Music Information Retrieval is mostly implemented by extracting meaningful traditional music features while Computational Auditory Scene Analysis relies acoustic features of speech and soundscapes that are not suitable to sound installations. Other forms of spatial analysis have been proposed by Collins et al.[4], and ambience extraction via neural networks by has been explored in [12]. Other forms of acoustic analysis could be implemented in order to better understand the sonic material of sound art. In general, computational analysis and classification of audio files has enormous potential as a creative tool for sound art installation that has yet to be explored more extensively.

\section{ACKNOWLEDGMENTS}

Thanks to my Master's Project advisors at the University of the Arts in Berlin: Dr. Julia Schröder and Thomas Koch, whose feedback and valuable input are included in this paper. Thanks to Markus Steffens and Carsten Seiffarth for their invaluable insights and interest in this project.

\section{REFERENCES}

[1] Carsten Seiffarth and Markus Steffens (Eds.). 2010. singuhr - horgalerie in parochial 1996-2006. Kehrer Verlag, Heidelberg.

[2] Carsten Seiffarth and Markus Steffens (Eds.). 2015. singuhr - horgalerie sound installation art in berlin. Kehrer Verlag, Heidelberg.

[3] Ina Ciumakova. 2018. Sound Art as Media Art Legacy: The Documentation of Endangered Practice. Ph.D. Dissertation. https://doi.org/10.13140/RG.2.2.36040. 78080

[4] Nick Collins, Peter Manning, and Simone Tarsitani. 2018. A New Curated Corpus of Historical Electronic Music: Collation, Data and Research Findings. Transactions of the International Society for Music Information Retrieval 1 (09 2018), 34-55. https://doi.org/10.5334/tismir.5 
[5] Helga de la Motte-Haber. 2010. Site-Specific Art. Ten Years of the Singuhr Sound Gallery. In singuhr horgalerie in parochial 1996-2006, Carsten Seiffarth and Markus Steffens (Eds.). Kehrer Verlag, Heidelberg, 20-23.

[6] Umberto Eco. 1989. The Open Work. Harvard University Press, Cambridge, MA.

[7] Andreas Engström and Åsa Stjerna. 2009. Sound Art or Klangkunst? A reading of the German and English literature on sound art. Organised Sound 14, 1 (2009), $11-18$.

[8] Kersten Glandien. 2016. Analysing Sound Art: Douglas Henderson's Fadensonnen In Expanding the Horizon of Electroacoustic Music Analysis, Simon Emmerson and Leigh Landy (Eds.). Cambridge University Press, Cambridge, 266-287.

[9] Alan Mardsen. 2016. Music Analysis by Computer: Ontology and Epistemology. In Computational Musical Analysis, David Meredith (Ed.). Springer International Publishing, Cham, Switzerland, 3-28.
[10] Volker Straebel. 2010. Vom Verschwinden der Klangkunst. Der Begriff der Klangkunst als wissenschaftsgeschichtliches Konstrukt. In Klangräume der Kunst, Peter Kiefer (Ed.). Kehrer Verlag, Heidelberg, 53-60.

[11] Jonathan Milo Taylor. 2009. ImMApp: An immersive database of sound art. Ph.D. Dissertation. University of the Arts London.

[12] Etienne Thuillier, Hannes Gamper, and Ivan Tashev. 2018. Spatial Audio Feature Discovery with Convolutional Neural Networks. https://doi.org/10.1109/ICASSP. 2018.8462315

[13] George Tzanetakis, Randy Jones, and Kirk McNally. 2007. Stereo panning features for classifying recording production style. In Proceedings of the 8th International Conference on Music Information Retrieval. Vienna, Austria.

[14] Juan Carlos Vasquez. 2019. Considerations on Sound Art Documentation: Theories and Case Studies. In Proceedings of the International Computer Music Conference. New York City, USA. 